\title{
PET - advanced nuclear imaging technology for medicine
}

\section{PET - zaawansowane obrazowanie nuklearne dla medycyny}

\author{
Hanna Piwowarska-Bilska ${ }^{\circledR}$, Aleksandra Supińska², Jacek Iwanowski \\ Adriana Tyczyńska³ , Bożena Birkenfeld ${ }^{1}$
}

\author{
1 Pomorski Uniwersytet Medyczny w Szczecinie, Zakład Medycyny Nuklearnej, ul. Unii Lubelskiej 1, 71-252 Szczecin \\ Pomeranian Medical University in Szczecin, Nuclear Medicine Department \\ ${ }^{2}$ Wielospecjalistyczny Szpital Wojewódzki w Gorzowie Wielkopolskim, Zakład Medycyny Nuklearnej, ul. Dekerta 1, 66-400 Gorzów Wlkp. \\ Multi-Specialist Regional Hospital in Gorzow Wielkopolski, Nuclear Medicine Department \\ ${ }^{3}$ Międzynarodowe Centrum Onkoterapii w Koszalinie, Affidea Polska, Zakład Fizyki Medycznej, ul. Chałubińskiego 7, 75-581 Koszalin \\ International Oncotherapy Centre Koszalin, Affidea, Medical Physics Department \\ $\triangle$ hanna.piwowarska.bilska@gmail.com
}

\begin{abstract}
Positron emission tomography (PET) is currently the most advanced diagnostic imaging technology along with well-known techniques like magnetic resonance imaging (MRI) and computed tomography (CT). Tremendous technical progress in engineering, imaging and radiopharmacy has provided the basis for impressive technological advances in the field of nuclear medicine over the past 50 years. Current nuclear medicine can be divided into 2 groups: the classic, which uses gamma-cameras for single photon emission computed tomography (SPECT) imaging, and
\end{abstract}

the more modern PET technique. The clinical PET technique requires: (i) patient administration of the radiopharmaceutical labelled with a positron emitter, (ii) recording of the gamma radiation emitted from the patient's body with a dedicated PET/ CT scanner, (iii) processing and analysis of recorded images. This article presents the basics of PET technology and research, and describes new technical trends introduced by the leading manufacturers of PET/CT scanners.

Keywords: positron emission tomography (PET); PET instrumentation; medical imaging.

\begin{abstract}
ABSTRAKT
Intensywny rozwój inżynierii obrazowania i radiofarmacji w ciągu ostatnich 50 lat stworzył podstawę dla zaawansowanych postępów technologicznych w dziedzinie medycyny nuklearnej. Współcześnie można podzielić ją na 2 grupy: klasyczną, wykorzystującą gamma kamery do obrazowania tomografii emisyjnej pojedynczego fotonu (SPECT) i nieco młodszą technikę pozytonowej tomografii emisyjnej (PET) - zaawansowaną technologicznie, diagnostyczną metodę obrazowania w medycynie, stosowaną wraz z bardziej znanymi technikami: obrazowaniem przy użyciu rezonansu magnetycznego (MRI) oraz rentgenowską
\end{abstract}

tomografią komputerową (CT). Kliniczna technika PET polega na: (i) podaniu pacjentowi radiofarmaceutyku znakowanego emiterem pozytonów, (ii) zarejestrowaniu emitowanego przez ciało pacjenta promieniowania gamma za pomoca dedykowanego skanera PET, (iii) rekonstrukcji i analizy zarejestrowanych obrazów. W tym artykule opisano podstawy technologii i badań PET, a także przedstawiono nowe trendy techniczne, wprowadzane przez wiodących producentów skanerów PET/CT. Słowa kluczowe: pozytonowa tomografia emisyjna (PET); aparatura PET; obrazowanie medyczne.

\section{INTRODUCTION}

It all began with the discovery of artificial radioactivity in the 1930s. This was followed by more than half a century of intensive technological progress in the field of diagnostic imaging techniques using ionizing radiation-dissemination, X-ray scanners, and gamma cameras. Until finally the cover of the Journal of Nuclear Medicine, published in April 1991, proclaimed the implementation of a new diagnostic imaging technology: Clinical PET: Its Time Has Come. Positron emission tomography (PET) was introduced as a research imaging technique in the early 1950s. Clinical PET systems became commercially available in the late 1970s.
We are currently in a time of intensive development of the clinical applications of PET technology, moving towards a search for new radiotracers, improved spatial resolution capability, increased scanner sensitivity, and reduced cost.

Positron emission tomography is a functional diagnostic method, representing a further step in the development of nuclear medicine. This technique allows clinicians to track organ function at a molecular level, thereby revealing intricate changes in individual patients earlier than other diagnostic methods. For this purpose, physiological substances present in the body or their analogs are labelled with radioisotopes which emit positrons - beta plus radiation. Positron emission tomography studies play a fundamental role in oncology, but 
their applications in cardiology, neurology, neuropsychology, diagnosis of infection, pharmacology, and preclinical studies cannot be ignored.

\section{POSITRON EMISSION TOMOGRAPHY RADIOPHARMACEUTICALS}

Compared to single photon emission computed tomography (SPECT), an imaging technique using radioisotopes which emit only 1 gamma photon of energy (99mTc), PET techniques have a much higher sensitivity and resolution due to the autocollimation of 2 annihilation gamma photons. Neutron deficient isotopes, which decay by positron emission, are important for PET studies. Inside human tissue the positron and electron annihilate each other and produce 2 photons with an energy of $511 \mathrm{keV}$, each travelling in opposite directions, which can be detected by the PET scanner [1]. The most clinically useful positron emitters are listed in Table 1.

There are 4 different methods of producing radioactive atoms for nuclear imaging: nuclear fission (reactor breeding), neutron activation processes, charged particle induced reaction - cyclotron production, and the radionuclide generator a chemical method [2]. Each method provides useful isotopes with differing characteristics for clinical and research applications. The $11 \mathrm{C}, 13 \mathrm{~N}, 15 \mathrm{O}$, and $18 \mathrm{~F}$ are low-molecular-weight isotopes which are produced in a cyclotron, a type of accelerator wherein the charged particles are accelerated by oscillating accelerating potentials perpendicular to a deflecting magnetic field (Fig. 1).

Radioisotope production via charged particle interaction is dependent on the large difference between the proton $(\mathrm{Z})$ number of the target material and the radionuclide. This allows for good physical and chemical separation procedures $[2,3]$. What is more, the radioisotopes are isotopes of elements which

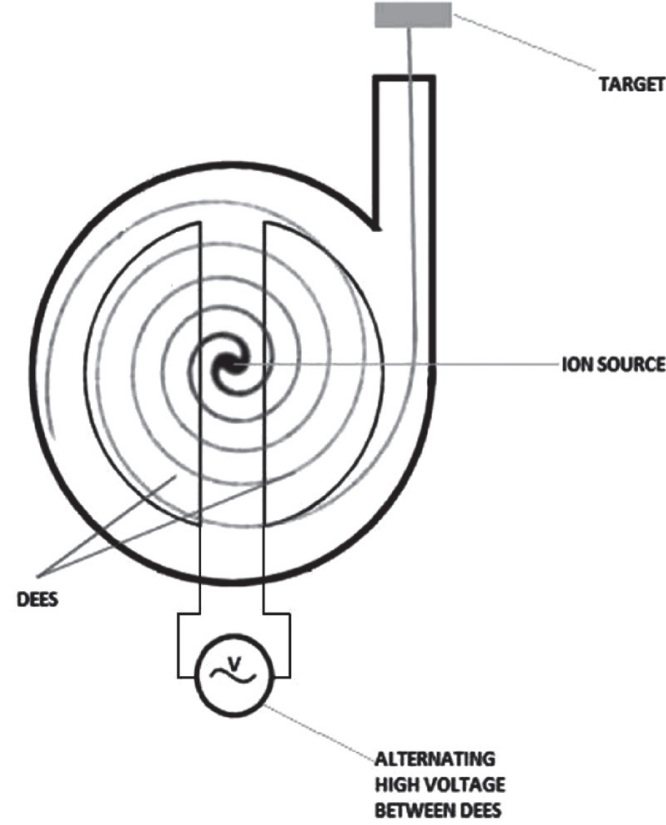

FIGURE 1. Illustration of the cyclotron's operation

form organic compounds in nature, such as carbon, oxygen, or nitrogen, or which easily react with organic compounds, such as fluorine. This allows for the use of a wide range of organic compounds in PET imaging such as sugars, amino acids, hormones, etc. The disadvantage of positron isotopes is their short half-lives, measured in minutes. The most popular is fluorine $18 \mathrm{~F}$, with a relatively long half-life of $110 \mathrm{~min}$. For other positron isotopes, the cyclotron producing them must be a relatively short distance from the PET scanner to allow for delivery while sufficiently high activity necessary for examinations remains. In the case of carbon $11 \mathrm{C}$ and nitrogen $13 \mathrm{~N}$, with half-lives of 20 and 10 min., respectively, the cyclotron must be located in the hospital.

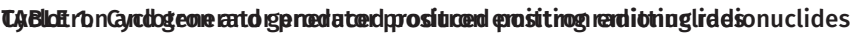

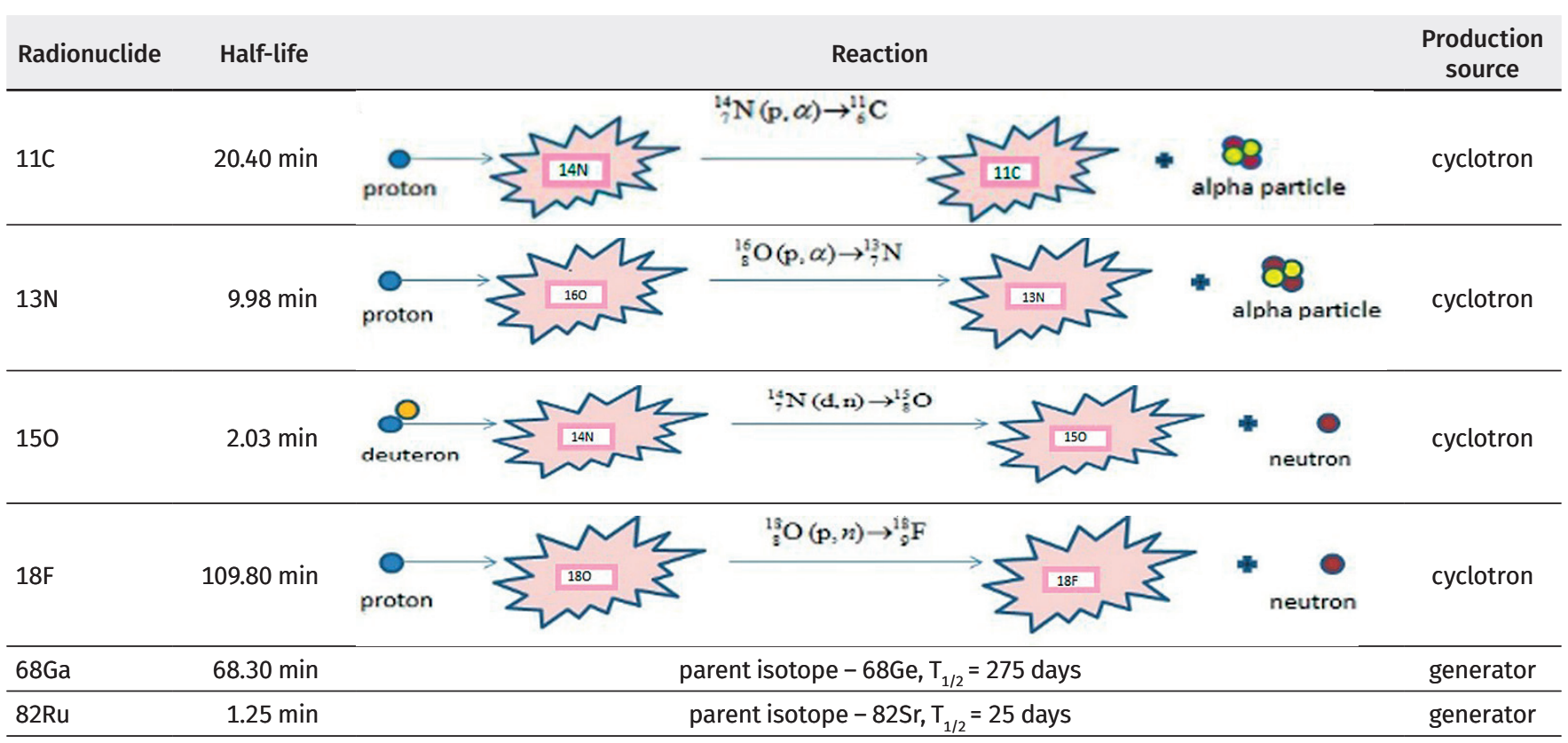


In PET imaging, positron emitters are used for labelling various types of molecules (known as vector molecules) which are selectively accumulated in certain cell types in animal or human organisms. The radiopharmaceuticals used in PET scans are made by attaching a radioactive atom to a chemical substance that is used naturally by the organ or tissue under examination during its metabolic processes.

One of the most popular radiopharmaceuticals used in PET is a glucose analog - 18F-labelled deoxyglucose (fluorodeoxyglucose - FDG). Glucose is preferentially utilized by tumour cells, related to overexpression of the GLUT glucose transporters and increased hexokinase activity. A PET investigation performed after FDG administration illustrates its physiological distribution and metabolism, and reflects the accelerated glycolytic rate of cancer cells [4].

In the last few years many new PET radiotracers for oncological imaging have been developed. The new PET tracer 18F-Sodium Fluoride (NaF) has higher sensitivity than conventional nuclear medicine scintigraphy with 99mTc-MDP for detecting bone metastases. Another new PET tracer used for evaluation of tumour hypoxia is $18 \mathrm{~F}$-fluoromisonidazole (FMISO), which is a powerful tool for evaluating rapidly growing tumours in head and neck cancer patients treated with radiotherapy. Also, $18 \mathrm{~F}$-fluoroethylcholine (FECH) is especially useful for restaging prostate cancer in patients with biochemical recurrence. In turn 3,4-Dihydroxy-18F-6-fluoro-L-phenyla lanine (FDOPA) was first developed to examine the transport of a dopamine precursor in Parkinson's' patients. Nowadays, FDOPA is a good tracer for staging and restaging medullary thyroid carcinoma, gastrointestinal cancer, different neuroendocrine tumours, and for detecting serotonin-expressing tumours [3, 5]. Another isotope, 18F-3-fluoro-3-deoxy-thymidine (FLT) is a radiolabelled thymidine analog, which is used to measure tumour cell proliferation and is a useful tool for early therapeutic assessment [5]. One of the most widely used amino acids is $18 \mathrm{~F}$ fluoroethyl tyrosine (FET) for assessment of brain tumours.

Carbon $11 \mathrm{C}$ is a short-lived isotope - its half-life is about $20 \mathrm{~min}$. Radiopharmaceuticals containing this radioisotope can be transported only over a short distance. But carbon has a huge advantage in that it occurs naturally in biologically active molecules. Swapping a single carbon atom in the molecule with the $11 \mathrm{C}$ isotope does not alter its physicochemical properties. As a result, the labelled molecule is activated in exactly the same physiological way as unlabelled particles. Carbon 11C-labelled compounds are used in investigation of neurological and cardiovascular processes. The 11C-Choline was firstly applied in brain tumours, and is now used for locating nodal and osseous metastases in prostate cancer patients with biochemical relapse. The $11 \mathrm{C}$-Methylspiperone (MSP) is mainly used to define dopamine-2-receptor density in patients with neurological disorders. The 11C-Raclopride can be applied for the detection of Parkinson's disease, and can be useful in schizophrenia patients $[4,5]$.

Ammonia $13 \mathrm{~N}$ (13N-NH3) is a useful compound which has been developed as a PET tracer for imaging and measuring cerebral and myocardial blood flows and coronary flow reserve. In clinical applications $13 \mathrm{~N}$ is of limited use when we compare it with other positron emitters, such as $11 \mathrm{C}$ and $18 \mathrm{~F}$, because of its short half-life ( $\sim 10 \mathrm{~min})$.

The 150-Water $\left(\mathrm{H}_{2} 150\right)$ is commonly used to assess cerebral and myocardial perfusion, but a better perfusion agent labelled with 150 is n-150-Butanol, which is used for blood flow measurements in the brain and other organs [5].

For imaging centres without a cyclotron, radionuclide generators are useful. For example, isotope 68Ga can be obtained from a 68Ge-68Ga generator. The parent isotope 68Ge's half-life is long enough that the generator can be transported over long distances and can be a source of $68 \mathrm{Ga}$ for labelling peptides and other tracers for periods of up to 1 year. Somatostatin analogues labelled with 68Ga have found a very important application in neuroendocrine tumour imaging. There is increasing interest in the potential application of 68Ga for labelling other tracers. For example imaging with PSMA-HBED labelled with 68Ga targets the prostate-specific membrane antigen expressed in metastatic prostate cancer. Another PET radiopharmaceutical obtained from a generator is the ultra-short-lived $82 \mathrm{Ru}$, which is very useful for PET imaging of myocardial blood flow $[6,7]$.

\section{POSITRON EMISSION TOMOGRAPHY INSTRUMENTATION}

Hybrid imaging is standard procedure in nuclear medicine nowadays. A typical PET/CT scanner designed for clinical use is shown in Figures 2A and 2B. This imaging system consists of 3 main components: a PET scanner, a CT scanner, and a patient bed. The major component inside the Computed Tomograph is an X-ray tube. The heart of the PET scanner is a scintillation detector.

\section{Scintillation detectors}

The technology behind imaging exams in nuclear medicine is based on detection of appropriate gamma photons, which have a strictly defined energy level. In order to achieve this, scintillation crystals, among others, are used. All radioisotopes used for PET imaging are positron emitters. The mechanisms of PET imaging involve registering 2 gamma rays with an energy of $511 \mathrm{keV}$, which are created as a result of the annihilation of a positron with an electron inside the patient's body. Photons disperse within a $180^{\circ}$ degree angle from each other, and have to be registered in a matter of nanoseconds, the so-called time window.

It is essential to choose the right material for the detector. The crystal should be characterized by a high probability of stopping photons with a given energy, high density, good energy resolution, short scintillation time, and the right amount of light output for a single photon. Depending on the density and mass number of the element, it is possible to determine its effective stopping power by measuring the distance that a photon must cover before its energy is accumulated. During 

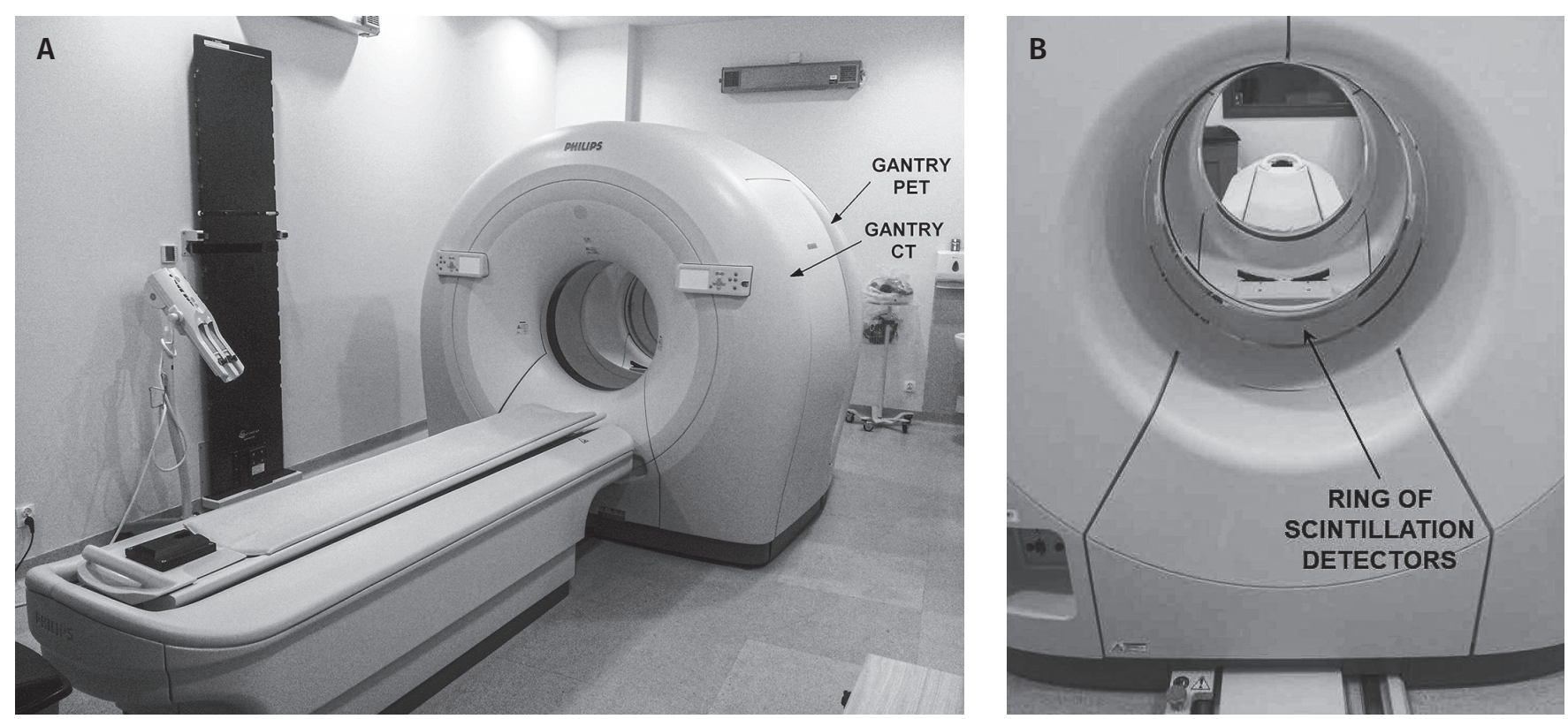

FIGURE 2. Philips PET/CT system, model TrueFlight Select: A) a view from the side of the patient bed; B) the view from the back of the scanner with the marked detector inside the PET ring

the interaction of the photon with the detector material, excitation of the atom takes place, and while it falls to its basic state it emits radiation in the form of a light photon. This phenomenon determines the specific disintegration time for each detector. It defines the dead time and the maximum number of counts possible for the scanner to register [2].

Early PET scanners were based on NaI(Tl) (sodium iodine doped with thallium) scintillation crystals. In the 1970s, bismuth germinate (BGO) was discovered and replaced $\mathrm{NaI}(\mathrm{Tl})$ in PET. However, the BGO crystal parameters were still not ideal for PET. Other types of crystals for PET detectors have also been used, such as: Barium Fluoride $\left(\mathrm{BaF}_{2}\right)$ or Gadolinium Oxyorthosilicate (GSO). In the late 1980s, lutetium oxyorthosilicate (LSO) was discovered and then other lutetium-based scintillators (LBS) such as lutetium-yttrium (LYSO) and lutetium fine silicate (LFS) were also found. Currently, the most popular scintillation crystals used in PET scanners are LSO and LYSO $[2,8]$.

The use of scintillation crystals with short disintegration time facilitates improvement of the measurement accuracy of the time of the initiated reaction, and use of a smaller coincidence window, which results in elimination of coincidental phenomena. So far, no material has been found that would allow building of an ideal detector that would meet all the characteristic requirements. Bismuth germinate is characterized by a high photon stopping power, but has too long a scintillation disintegration time [5] in comparison to LSO and LYSO (Tab. 2), which are similar to one another, and meet the characteristics of a so-called "quick" scintillator. An optimal stopping power and short scintillation disintegration time ensure measurement of a high number of counts [5].

An important value due to the quality of the acquired tomographic images is information on the time of flight (TOF) of gamma quanta from the moment of their emission to registration by detectors. The use of flight time information in PET was already proposed in the 1980 s for $\mathrm{CsF}$ and $\mathrm{BaF}_{2}$ crystals. Real development and renewed interest in this subject came with the invention and introduction of new, fast and efficient scintillation crystals such as $\mathrm{LSO}$ and $\mathrm{LaBr}_{3}$. Conventional PET reconstruction uses the time-of-flight information only to identify the line along which the annihilation occurred. It is unable, though, to determine which voxel along the line is the source of the two photons; therefore all the voxels along the line are given the same probability of emission. Time of flight PET uses the time-of-flight difference to better locate the annihilation position of the emitted positron. The inclusion of TOF information narrows the studied region, thus reducing the number of false events and improving the signal-to-noise ratio, which in turn improves the sharpness of the reconstructed image. In clinical trials, this translates directly into shortening patient examination time.

\section{Photomultiplier tubes}

Photomultiplier tubes (PMT) are another important element in the construction of PET scanners, or in some cases, semiconductor detectors (photodiode). They ensure the conversion of light photons created in the scintillation crystal into electrical impulses. Photomultiplier tubes are also used due to their ability to strengthen the light signal.

The construction of a photomultiplier (Fig. 3), placed in a long glass bubble, consists of an anode, a cathode, and ten dynodes. A light impulse from a crystal is transported through optical fibre or optical grease to a photocathode, which becomes excited. The photocathode is usually an alloy of cesium and antimony that releases electrons following absorption of light photons. A high voltage is applied between the photocathode and the anode (about $1 \mathrm{kV}$ ) with increments (about $100 \mathrm{~V}$ ) between the dynodes. When light photons from the detector strike the 
TABLE 2. Properties of some scintillators used in PET

\begin{tabular}{|c|c|c|c|c|c|c|}
\hline Detectors & Materials & $\begin{array}{l}\text { Density } \\
\left(\mathrm{g} / \mathrm{cm}^{3}\right)\end{array}$ & $\begin{array}{c}\text { Atomic } \\
\text { number } \\
\text { Z }\end{array}$ & $\begin{array}{l}\text { Scintilator } \\
\text { decay time } \\
\text { (ns) }\end{array}$ & $\begin{array}{l}\text { Energy } \\
\text { resolution }\end{array}$ & $\begin{array}{l}\text { Linear attenuation } \\
\text { coefficient } \\
\left(\mathrm{cm}^{-1}\right)\end{array}$ \\
\hline BGO & $\mathrm{Bi}_{4} \mathrm{Ge}_{3} \mathrm{O}_{12}-$ bismuthgermanite & 7.13 & 74 & 300 & 10.0 & 0.95 \\
\hline LSO & $\mathrm{Lu}_{2} \mathrm{SiO}_{5}: \mathrm{Ce}$ - lutetiumoxy orthosilicate & 7.40 & 66 & 40 & 10.1 & 0.87 \\
\hline LYSO & LuYSiO $_{5}: \mathrm{Ce}$ - lutetium-yttrium oxyorthosilicate & 7.20 & 65 & 50 & 20.0 & 0.87 \\
\hline
\end{tabular}

Linear attenuation coefficients and energy resolution are quoted for $511 \mathrm{keV}$

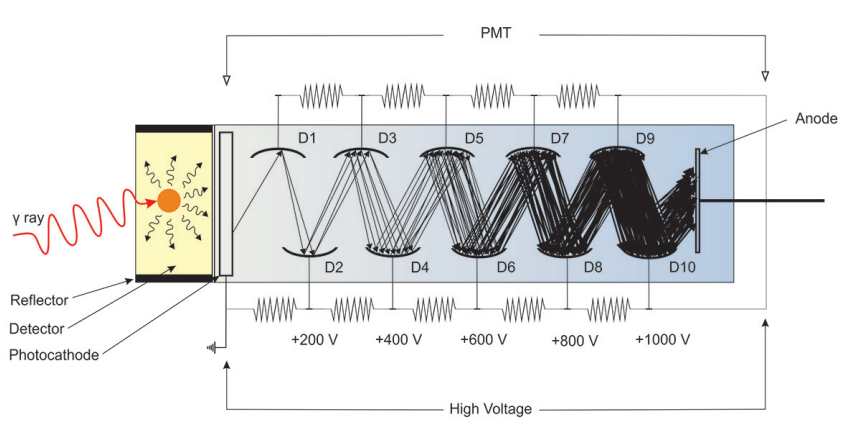

FIGURE 3. The principle of operation of the photomultiplier includes a photocathode, a series of dynodes, and an anode

photocathode, electrons are emitted, which are accelerated toward the next dynode by the voltage difference between the dynodes. Each of these electrons is again accelerated toward the next dynode and more electrons emitted, and as a result, a stream of current reaches the cathode. Transported to the linear amplifier and classified by a Pulse Height Analyzer, it gets registered in the form of counts on an image map or displayed on a screen $[2,8]$.

The traditional photomultiplier tube is still the most common photo-detector used in scintigraphic imaging devices. However, new detector technologies are entering the world of medical imaging. Nowadays, semiconductor detectors are available to replace traditional photomultiplier tubes. Semiconductor PET detectors have higher spatial resolution and lower scatter noise than conventional photomultiplier technology. Thus, the latest commercially available PET/CT scanners use digital photon counting technology in their digital silicon detectors.

\section{Block detectors}

The detector architecture first used in PET scanners was based on connecting one crystal with one photomultiplier. This allowed for achievement of good spatial resolution with the device by using a large number of detectors, with a proportional number of PMT. The production of such scanners became impractical due to the costs generated by the number of installed photomultipliers in the whole imaging system, which could reach the thousands [5].

In order to improve the spatial resolution of scanners, the crystals were made smaller, which then caused another problem related to the excessively large size of photomultipliers in relation to the scintillation detector. Due to financial and construction limitations, a block model for a detector was designed.

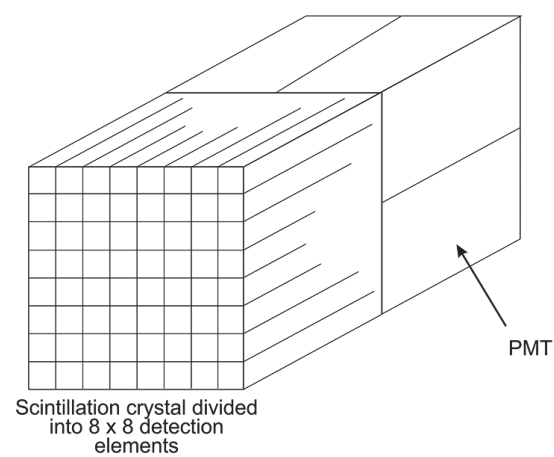

FIGURE 4. Construction of a block detector with $8 \times 8$ detection elements

Four PMT were used to build it, connected to a scintillation crystal divided into $8 \times 8$ detection elements. For this, appropriately deep cuts were made and filled with white reflective material. The purpose of this was to ensure proper distribution of photons delivered to the photomultipliers. The construction of the block detector can be found in Figure $4[2,8]$.

The incident annihilation photon is converted into light in the scintillator and the sharing of light between the 4 photomultiplier tubes identifies the scintillator element and localizes the incident photon. The output from the block detector is the coordinates of the element ( $\mathrm{x}, \mathrm{y}$ ) and the energy (E) of the photon obtained by summing the light produced in the scintillator. In order to improve the block model detector, a connection of 4 corners from various blocks to one photomultiplier was designed. This method allows for a decrease in the number of PMT used in the PET scanner but necessitates the use of larger sized tubes. It also significantly worsens dead time, but improves spatial resolution $[3,5,8]$.

In parallel with the technical developments in PET instrumentation, improvements have been made in the reconstruction algorithms. Initially, filtered projection (filtered back projection-FBP) was used to reconstruct tomographic images, which over time was supplemented with further types of filters to improve image quality. With the development of PET, the need to develop completely new methods of image reconstruction arose. These were the iterative methods that were soon applied to the reconstruction of SPECT images. In the iterative methods (Expectation Maximization Maximum Likelihood EMML, Ordered Subset Expectation Maximization - OSEM, Interpolation of Projections by Contouring - IPC, Iterative Wallis - ITW, Iterative Chang - ITCHG), the data from each projection is compared with certain assumptions (estimates), and the resulting differences are used to modify these assumptions 
(estimates), which are re-compared with the data obtained in the study - this process is repeated many times.

\section{Hybrid imaging: PET-CT and PET-MRI}

Positron emission tomography scanner provides functional images of the distribution of radiopharmaceuticals in the patient's body. Compared to high-resolution scans such as CT or magnetic resonance imaging (MRI), nuclear medicine images have lower resolution, which causes problems in locating lesions in organs and tissues. The combination of PET and CT technologies (Fig. 5) began an era of hybrid scanners and resulted in huge technological development in the field of nuclear medicine. The result of hybrid imaging is a fused image accurate information about the structure and metabolism of the tissue in one. The main advantage of PET-CT scans is an increase in specificity facilitated by location of abnormal accumulation of the tracer. In PET-CT scanning, in addition to its use in fusion of PET and CT images, the CT transmission scan can be conveniently used to perform attenuation correction of PET emission data.

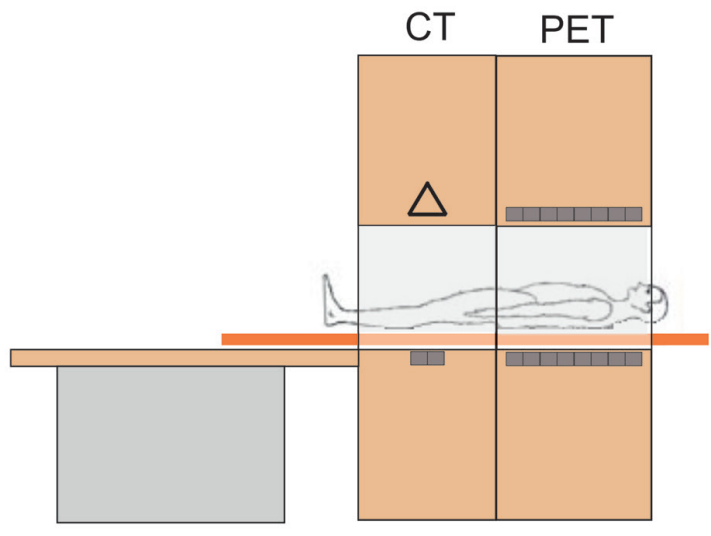

FIGURE 5. Combining PET and CT systems

Currently, the proper matching of PET and CT scans in a fused image is achieved using software which contains algorithms that find specific points of reference in both scans. Previously, special markers which had to be seen on both scans were used for this purpose. The markers were placed either on the skin surface or inside the patient's body. There was also a method that involved manual outlining of the body contour and subsequent image alignment. This method was subject to the most significant alignment errors. Despite the use of appropriate algorithms for fusion tests, there are still limitations related to motion artifacts, mainly caused by the patients' breathing. Also, the sequential nature of the examinations (first CT, then PET) and the difference in their durations cause inaccuracies in PET-CT image fusion. The development of a respiratory gating system improved the discrepancies which appeared in the conjunction of images but extended the duration of the scan $[3,8,9]$.

The PET-CT imaging has received excellent recommendations in clinical trials, which optimized diagnostics and therapeutic protocols thanks to the functional and anatomical images. However, X-ray tomography imposes limitations due to poor contrast of soft tissues despite the use of contrast agents. Furthermore, in order to achieve good quality images, the radiation dose from the CT scanner is still too high. In this case, the ideal solution is MRI, which provides excellent contrast of soft tissues in regions such as the brain and abdomen. Such examinations can be carried out without much risk to the patient because they do not require the use of ionizing radiation $[5,9]$.

Combining the 2 systems, PET and MRI, which are so different, creates unusually big technological problems. The greatest difficulty is the development of a scanner that allows the 2 devices to work together without interference and without compromising their efficiency. The classic PET scanner uses PMT that are sensitive to magnetic fields, which disqualifies them for use near magnetic fields as well as in the PET-MRI scanner itself. Initially, a separate structural model was used in which the devices where placed at a distance from each other. However, this solution caused great difficulties due to the size of the device as well as problems with image acquisition. Another technological innovation was connecting detectors to fibre-optic cables that were supposed to transport the signal at a distance from the magnetic field. Finally, screening of the constructional parts started to be used. However, the major solution came from technological development that allowed for the use of avalanche photodiodes (APD), which do not lose efficiency in strong magnetic fields and are smaller than PMT. Thanks to the special photodiodes, combining PET and MRI in a single device has become easier. Technological progress should enable multimodal data acquisition that will allow for accurate spatial and temporal data recording without motion artifacts. Such a solution is the use of PET and MRI in a single gantry $[9,10]$.

Mainly due to 3 producers of PET scanners - Siemens, GE Healthcare, and Philips - PET imaging technology is developing dynamically, both in terms of equipment and software. In order to improve the quality of data, Siemens is using the Flowmotion effect, which replaces the step method by a system of continuously shifting the patient table during data acquisition. This solution significantly improves the accuracy of the quantitative analysis of images and gives a better uniformity of the image along the long axis of the patient. Worth noting is the variety of methods aimed at improving the sensitivity of PET-CT scanners, for example, replacing the analog photomultiplier with a semiconductor in the detector. The new LightBurst detector electronics proposed by GE guarantee a higher count rate, and hence higher sensitivity, which can significantly shorten the duration of the standard oncology examination - whole-body, and reduce the activity of the radiotracer administered to a patient.

\section{SOME CLINICAL USES OF PET-CT}

Positron emission tomography is a non-invasive technique that allows for visualization and evaluation of the functioning of 
the patient's organs and tissues. Some abnormalities in human tissues can be detected with PET technology at earlier stages than by CT or magnetic resonance. Positron emission tomography can be used for detection of pathological lesions in cardiology and neurology, but the majority of investigations are done in oncology patients. This is facilitated by the use of specific radiotracers which accumulate in pathological lesions. The PET-CT diagnostic examination exposes patients to low doses of ionizing radiation. The mean effective dose from PET-CT procedures with different radiopharmaceuticals ranges between 4.6 and $20.0 \mathrm{mSv}$, but the risk of cancerogenesis or development of genetic disorders due to exposure to radiation is negligible. The biggest influence of the PET-CT technique on clinical management is in oncology, where it allows whole body examination of patients in order to:

- identify cancerous lesions,

- stage the cancer,

- plan treatment before surgery, radiotherapy or chemotherapy,

- assess the treatment's effectiveness,

- follow up after treatment,

- detect the cancer's recurrence.

Hybrid techniques like PET performed together with CT or MRI have some additional benefits. They allow, apart from metabolic and functional abnormalities, also for visualization of the morphological structure of the patient's body. This gives better location of abnormal lesions, and is necessary for attenuation correction of nuclear medicine images.

To depict the radiopharmaceutical accumulation in the organ the standardized uptake value (SUV) is calculated. This is "the ratio of the radiopharmaceutical tissue concentration

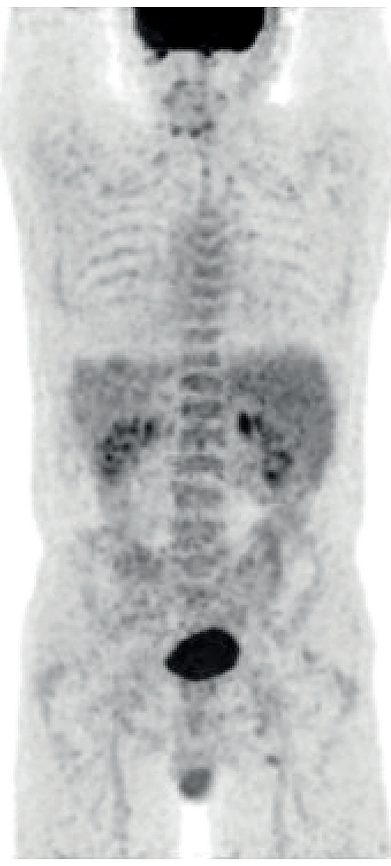

PET SCAN

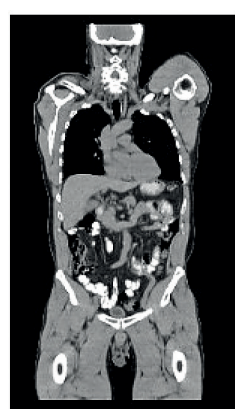

CT SCAN

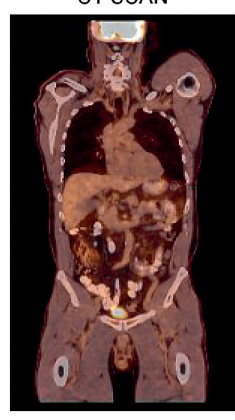

CT-PET FUSED IMAGE

FIGURE 6. PET-CT with FDG - normal pattern. Physiological FDG uptake in brain, liver, kidneys, and bone marrow. Radioactive urine collection in urinary bladder in Becquerel/gram (in Bq/g) to the injected dose in Bq divided by the body mass in grams" [11].

$$
S U V=\frac{(\text { concetration }[\mathrm{Bq} / \mathrm{g}] / \text { injected dose }[\mathrm{Bq}])}{(\text { body mass }[\mathrm{g}])}
$$

It is assumed that increased SUV values indicate higher glucose uptake which is consistent with cancer cells' abnormal metabolism. In oncology it is useful for assessment of tumour malignancy and for monitoring and staging the cancer.

As previously mentioned, in clinical PET scanning the most commonly used radiotracer is FDG. Flourodeoxyglucose shows areas of abnormally increased glucose accumulation in tumour cells.

The FDG dose for each patient is individually calculated and depends on the type of scanner, examination mode, and the patient's weight. It is always the minimum amount of radiotracer activity required to achieve high quality diagnostic images. In Poland, the recommended activity of FDG administered to adults is $4 \mathrm{MBq}$ per kilogram of patient's weight with a suggested activity of not more than $450 \mathrm{MBq}$ [12]. The activity of FDG administered to children should be assessed on the basis of the patient's body weight in relation to the activity administered to adult patients with a typical body structure, according to the regulation of the Polish Minister of Health of 18.02.2011 [13].

Below there are some examples of clinical images (Fig. 6, $7,8,9$, and 10) from the archives of the Affidea PET-CT Medical Centre in Szczecin. These images were obtained using the TrueFlight Select PET-CT Philips scanner.

The most important clinical application of PET-CT is in oncology, but there are some other clinical indications. In cardiology

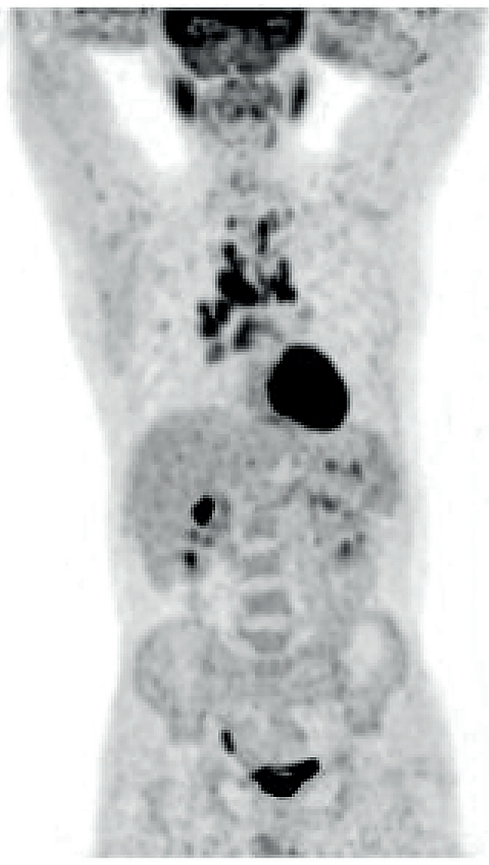

PET SCAN

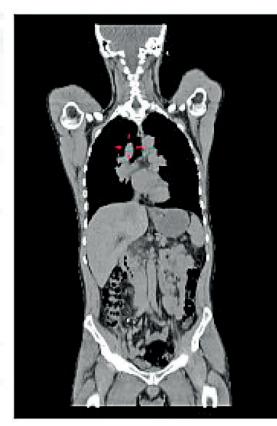

CT SCAN

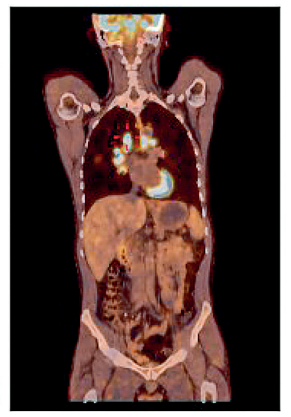

CT-PET FUSED IMAGE
FIGURE 7. PET-CT with FDG in a patient with Hodgkin's lymphoma. Enlarged, metabolically active lymph nodes in the mediastinum. Physiological FDG uptake in brain, heart, kidneys, and urinary bladder 


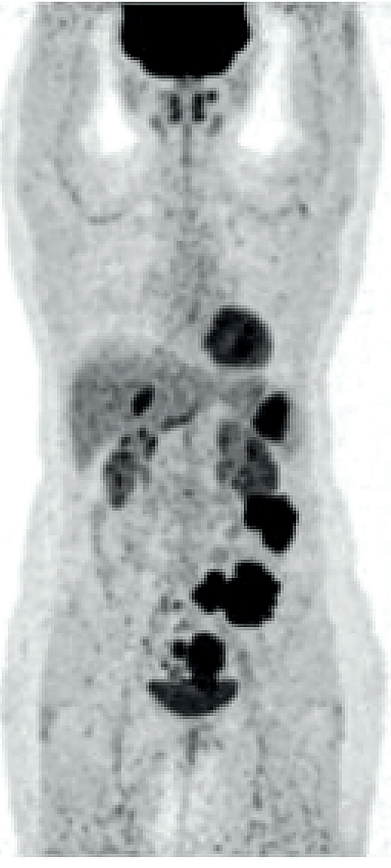

PET SCAN

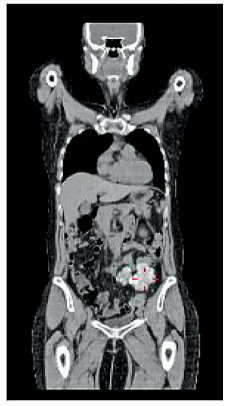

CT SCAN

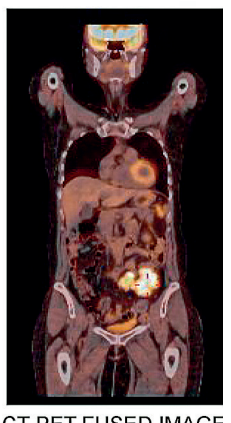

CT-PET FUSED IMAGE
FIGURE 8. PET-CT with FDG in a patient with ovarian cancer after surgical treatment. Recurrence of the disease - multiple metastases in the liver, spleen, and abdomen

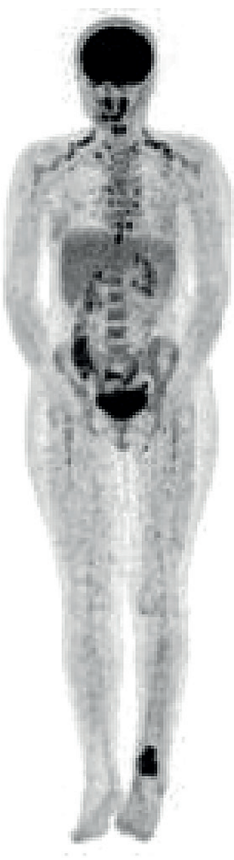

PET SCAN

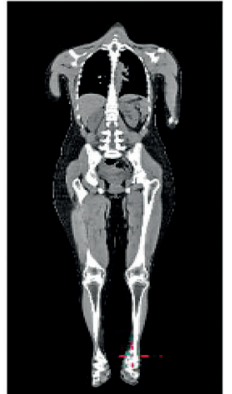

CT SCAN

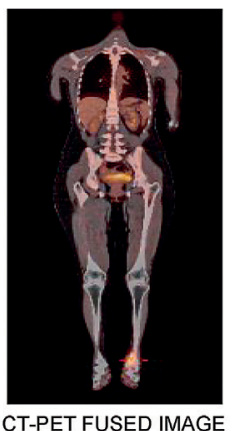

CT-PET FUSED IMAGE
FIGURE 10. PET-CT with FDG in a melanoma patient - primary lesion on the skin of the left distal leg. Physiological "brown tissue" in both supraclavicular regions

it is used for assessment of myocardial perfusion and metabolism, including diagnosis of coronary artery disease and myocardial viability. The PET-CT imaging allows for assessment of whether the patient will benefit from invasive treatment such as angioplasty and stenting, coronary artery bypass surgery, or another procedure.

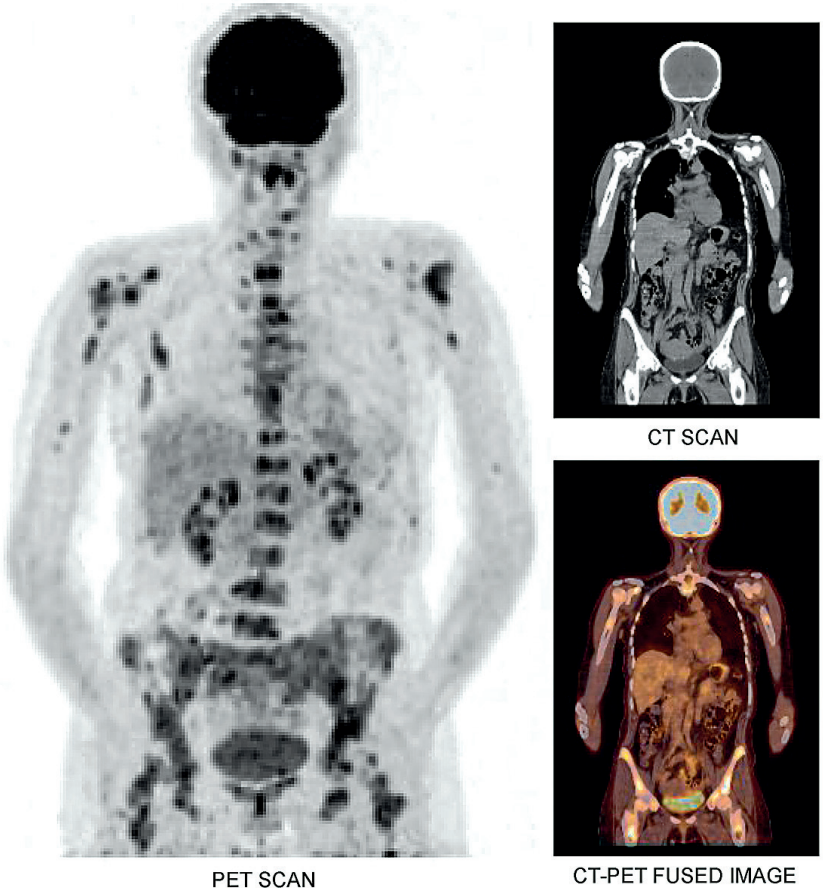

FIGURE 9. PET-CT with FDG in a breast cancer patient - multiple bone metastases

In neurology, PET-CT with FDG or other tracers is useful for diagnosis, treatment planning, and monitoring of various diseases, like epilepsy, dementia (Alzheimer's disease), movement disorders (Parkinson's disease), or brain tumours, as well as many others.

\section{CONCLUSIONS}

Modern medicine requires excellent technical tools for diagnostic imaging of the human body structure, function, and metabolism. Therefore, there is a bright future for hybrid scanners such as PET-CT or PET-MRI. It seems that the leaders of the global diagnostic imaging market are not yet finished with the development of hybrid techniques. We are waiting for new solutions that will allow for a shorter acquisition time, better image resolution, and improved image quality and its quantitation, which will result in greater confidence in medical diagnoses. Advances in more specific areas such as generator-based PET radiopharmaceuticals should also be considered. Therefore, it is certain that multimodal medical imaging is going to play a major role in the diagnosis and management of diseases for the foreseeable future.

\section{REFERENCES}

1. Hogg P, Testanera G, editors. Principles and practice of PET/CT: part 1: a technologists guide. Vienna: European Association of Nuclear Medicine; 2010.

2. Saha GB. Basics of PET imaging: physics, chemistry, and regulations. New York: Springer Science+Business Media LLC; 2010. doi: 10.1007/978-1-4419-0805-6. 
3. Rudin M. Molecular imaging: Basic principles and applications in biomedical research. 2nd ed. London: Imperial College Press; 2013.

4. Elsinga PH. Present and future of PET-radiopharmaceuticals. Nuclear Medicine Review 2012;15(C):13-6.

5. Peller P, Subramaniam R, Guermazi A, editors. PET-CT and PET-MRI in Oncology: A Practical Guide. Berlin, Heidelberg: Springer; 2012. doi: 10.1007/978-3-642-01139-9.

6. International Atomic Energy Agency. Nuclear Technology Review: Annex VI. Advances in medical radiation imaging for cancer diagnosis and treatment. Vienna; 2006; INIS-XA--909.

7. Nuclear Energy Agency. Beneficial Uses and Production of Isotopes. France: OECD; 2005.

8. Cherry SR, Dahlbom M, Phelps ME, editors. PET: physics, instrumentation, and scanners. New York: Springer Science+Business Media LLC; 2006. doi: 10.1007/0-387-34946-4.
9. Delso G, Ziegler S. PET/MRI system design. Eur J Nucl Med Mol Imaging 2009;36 Suppl 1:S86-92. doi: 10.1007/s00259-008-1008-6.

10. Pichler BJ, Judenhofer MS, Pfannenberg C. Multimodal imaging approaches: PET/CT and PET/MRI. Handb Exp Pharmacol 2008;(185 Pt 1):109-32. doi: 10.1007/978-3-540-72718-7_6.

11. Quality assurance for PET and PET/CT systems. Vienna: International Atomic Energy Agency; 2009. IAEA human health series; no. 1.

12. Polish Official Journal of the Ministry of Health. Notice of the Minister for Health of 6 Nov 2013 on the publication of the list of standard radiological procedures of nuclear medicine.

13. Regulation of the Polish Minister of Health of February 18, 2011 on the conditions of safe use of ionizing radiation for all types of medical exposure. Journal of Laws of the Republic of Poland 2011 No.51 Item 265 with further amendments. 